\title{
Bevacizumab combined with chemotherapy for glioblastoma: a meta-analysis of randomized controlled trials
}

\author{
Shou-Bo Yang ${ }^{1}$, Kai-Di Gao ${ }^{2}$, Tao Jiang ${ }^{3}$, Shu-Jun Cheng ${ }^{1}$ and Wen-Bin Li ${ }^{1}$ \\ ${ }^{1}$ Department of Oncology, Beijing Shijitan Hospital, Capital Medical University, Beijing, China \\ ${ }^{2}$ Beijing Rehabilitation Hospital of Capital Medical University, Beijing, China \\ ${ }^{3}$ Department of Neurosurgery, Tiantan Hospital, Capital Medical University, Beijing, China
}

Correspondence to: Wen-Bin Li, email: liwenbin@ccmu.edu.cn

Keywords: bevacizumab, chemotherapy, glioblastoma, meta-analysis, prognosis

Received: October 24, $2016 \quad$ Accepted: March 22, $2017 \quad$ Published: April 07, 2017

Copyright: Yang et al. This is an open-access article distributed under the terms of the Creative Commons Attribution License 3.0 (CC BY 3.0), which permits unrestricted use, distribution, and reproduction in any medium, provided the original author and source are credited.

\section{ABSTRACT}

Bevacizumab, as antibodies, were applied to inhibit tumor angiogenesis by preventing activation of vascular endothelial growth factor receptor. We analyzed four clinical trials, including 607 patients, to investigate the efficacy and safety of bevacizumab when combined with chemotherapy for the treatment of glioblastomas. Results demonstrated that bevacizumab when combined with chemotherapy improved progression-free survival (HR $=0.66 ; 95 \%$ CI 0.56-0.78; $p<0.00001)$ compared with bevacizumab or chemotherapy alone. Furthermore, overall survival showed insignificant difference between two arms (HR 0.99; 95\% CI 0.8-1.21; $p=0.92$ ). However, we found that patients treated with bevacizumab-containing therapy reported increased objective response rate (OR 1.85, 95\% CI 1.17-2.93; $p=0.009$ ), but more treatment-related adverse events (OR 1.75; 95\% CI 1.09-2.83; $p=0.02$ ).

\section{INTRODUCTION}

Glioblastoma (GBM, WHO grade IV) is the most common brain tumor, accounting for $15.1 \%$ of all primary brain tumors and $46.1 \%$ of all malignant brain tumors. The assessed number of cases of GBMs in the United States for 2015 and 2016 are 11,890 and 12,120, respectively [1]. For newly diagnosed GBMs, the regimen developed by Professor Stupp is considered as standard therapy, comprising maximal resection, radiochemotherapy, and temozolomide maintenance therapy [2]. However, GBM is typical of aggressiveness and always indicate a poor prognosis. The median survival rate of GBM patients is approximately one year, and only $5.1 \%$ can survive five years post diagnosis [1].

GBMs are composed of densed and highly disorganized vessels $[3,4]$.These highly disorganized vessel architectures critically contribute to rapid tumor growth and resistance to radiotherapy and chemotherapy. Tumor angiogenesis depends on multiple mechanisms. Vascular endothelial growth factor (VEGF) is a crucial factor in these signal passways affecting angiogenesis [5]. GBM cells present a high level of VEGFs and were correlated to aggressiveness and prognosis [6]. Thus, the inhibition of VEGF is assumed to slow down tumor growth and enhance the effects of radiotherapy and chemotherapy $[7,8]$.

Bevacizumab is a monoclonal antibody that targets VEGF-A to inhibit its downstream signal activity by restraining interaction with the VEGF receptor. It was the first drug targeting tumor angiogenesis approved by the FDA and was applied for the treatment of GBMs since 2009 [9]. Various Phase II clinical trials with bevacizumab single-agent therapy showed promising results in recurrent GBMs with progression-free survival (PFS) at six months of $29 \%-46 \%$ [10-12]. However, further studies found no improved overall survival (OS) or relatively high response rate [13]. Researchers implied that bevacizumab inhibits tumor momentarily, but promote tumor growth in the long run [14-16]. The combination therapy with bevacizumab and other chemotherapies was supposed to be more effective. Hence, several trials have been initiated to explore the efficacy of combination therapy.

In this meta-analysis, we aimed to collect data from high-quality randomized controlled trials to assess the efficacy and safety of bevacizumab combined with chemotherapy versus single-agent therapy for new diagnosed and recurrent GBMs. 


\section{RESULTS}

\section{Study selection}

A total of 815 articles were identified by searching database (110 studies from Pubmed, 679 from Embase and 26 from Cochrane library). The identification of the four studies included as shown by a flow chart in Figure 1. The risk of bias for each eligible study is summarized in Figure 2. Four trials were open-labeled and deprived information about allocation concealment [20-23]. Two trials deprived information about random sequence generation $[20,23]$.

\section{Characteristics of the included studies}

The details of baseline characteristics in five included studies are shown in Table 1. A total of 607 patients were enrolled in these multicenter studies (310 patients randomized to bevacizumab combination therapy group and 297 to control group). All patients were above 18 years old and histologically confirmed GBMs. Four studies were multicenter, unblended and phase II randomized clinical trials. Three trials focused on recurrent GBMs, and one other trial focused on newly diagnosed GBMs. The experimental group regimens were bevacizumab combined with irinotecan, carboplatin and lomustine, whereas the control group regimens were bevacizumab monotherapy or chemotherapy alone, correspondingly [20-23].

\section{PFS}

Three trials reported prolonged median PFS from experimental group to control group, other than one trial with same PFSs in both arms as presented in Table 1 [20-23]. Figure 3 shows the meta-analysis results that the combination of bevacizumab with chemotherapy significantly improved PFS compared with bevacizumab or chemotherapy alone (HR 0.66 ; 95\% CI $0.56-0.78$; $p<0.00001)$. Heterogeneity among the trials was not statistically significant $\left(\chi^{2}=5.74 ; p=0.12 ; \mathrm{I}^{2}=48 \%\right)$.

A subgroup analysis based on the line of treatment was also performed. The results indicated that bevacizumab combined with chemotherapy prolonged PFS in recurrent GBM patients (HR 0.70; 95\% CI 0.57-0.85; $p=0.0005$; Figure 3).

OS

All four trials demonstrated insignificant statistical differences between experimental group and control group (Table 1) [20-23]. In the meta-analysis of the four trials, results from Figure 4 suggested that bevacizumab combined with chemotherapy was not associated with any significant improvement in OS (HR 0.99; 95\% CI 0.81-1.21; $p=0.92)$. Insignificant heterogeneity was found in pooled trials $\left(\chi^{2}=4.69 ; p=0.20 ; \mathrm{I}^{2}=36 \%\right)$.

The subgroup analysis outcomes made no difference with overall results above. There were insignificant statistical differences in recurrent GBM patients (HR 0.98; 95\% CI 0.77-1.24; $p=0.85$; Figure 4).

\section{ORR}

Three trials offered ORR values (including complete response and partial response), as shown in Table 1 [20, 22, 23]. As Figure 5 presents, pooled values were analyzed and established that bevacizumab combined with

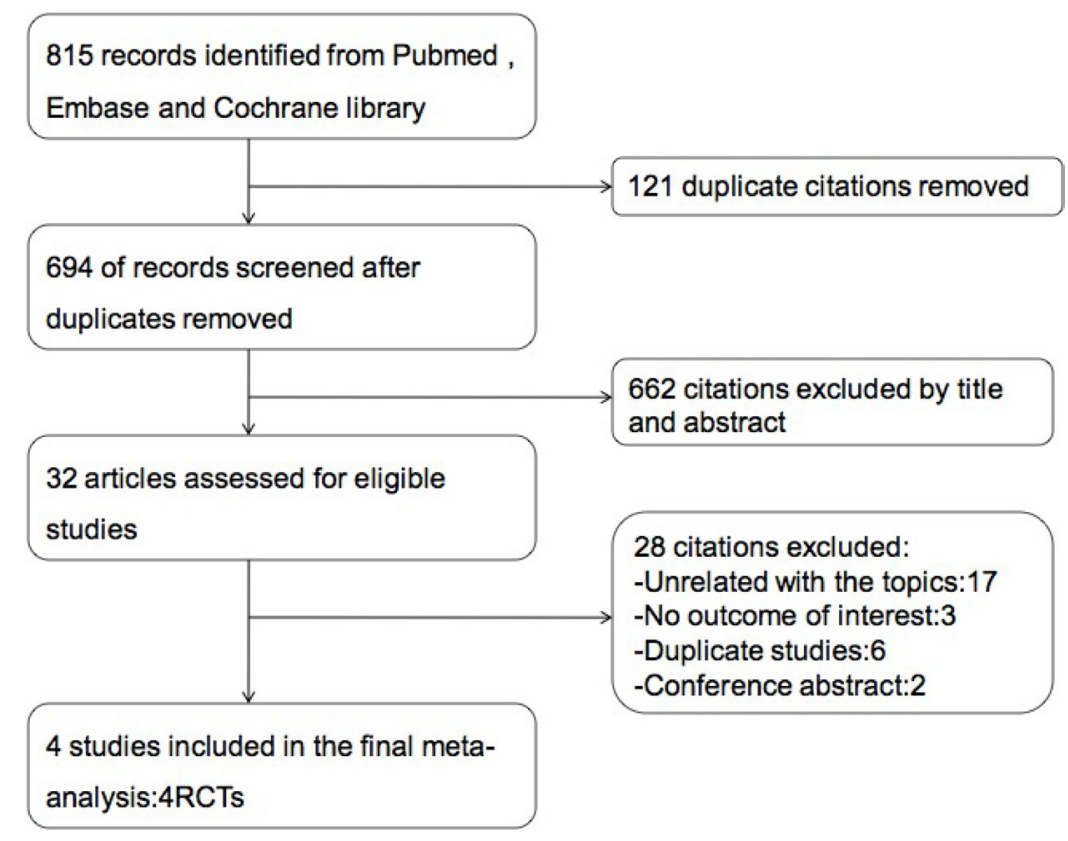

Figure 1: Flow chart of the literature research. 
Table 1: Baseline characteristics of the patients in the trials included in the meta-analysis

\begin{tabular}{|c|c|c|c|c|c|c|c|c|c|c|c|c|c|c|c|}
\hline \multirow[t]{2}{*}{ Study } & \multirow[t]{2}{*}{$\begin{array}{c}\text { Recruitment } \\
\text { period }\end{array}$} & \multirow[t]{2}{*}{$N$} & \multirow[t]{2}{*}{$\begin{array}{c}\text { Number } \\
\text { of } \\
\text { men }\end{array}$} & \multirow[t]{2}{*}{$\begin{array}{c}\text { Mean } \\
\text { age }\end{array}$} & \multirow[t]{2}{*}{$\begin{array}{l}\text { First-line } \\
\text { therapy }\end{array}$} & \multicolumn{2}{|c|}{ Intervention } & \multicolumn{2}{|c|}{$\begin{array}{c}\text { Median } \\
\text { PFS } \\
\text { (months) }\end{array}$} & \multicolumn{2}{|c|}{$\begin{array}{c}\text { Median OS } \\
\text { (months) }\end{array}$} & \multicolumn{2}{|c|}{ ORR } & \multicolumn{2}{|c|}{$\operatorname{AES}($ Grade $\geq 3)$} \\
\hline & & & & & & Exp & Con & Exp & Con & Exp & Con & Exp & Con & Exp & Con \\
\hline Field 2015 & 2010-2012 & 122 & $67(55 \%)$ & 55 & No & $\mathrm{BEV}+\mathrm{CAR}$ & $\mathrm{BEV}$ & 3.5 & 3.5 & 6.9 & 7.5 & $8(14 \%)$ & $4(6 \%)$ & $37(64 \%)$ & $36(58 \%)$ \\
\hline $\begin{array}{l}\text { Friedman } \\
2009\end{array}$ & 2006-2007 & 167 & $115(69 \%)$ & 55 & No & BEV + IRI & $\mathrm{BEV}$ & 5.6 & 4.2 & 9.2 & 8.7 & $31(37.8 \%)$ & $24(28.2 \%)$ & $52(66 \%)$ & $39(46 \%)$ \\
\hline $\begin{array}{l}\text { Herrlinger } \\
2016\end{array}$ & 2010-2012 & 170 & $114(67 \%)$ & 56 & Yes & BEV + IRI & TMZ & 9.7 & 5.99 & 16.6 & 17.5 & NA & NA & NA & NA \\
\hline Taal 2014 & 2009-2011 & 148 & 91 (61\%) & 57 & No & $\mathrm{BEV}+\mathrm{LOM}$ & BEV/LOM & 4 & $3 / 1$ & 12 & $8 / 8$ & $19(39 \%)$ & $20(22 \%)$ & NA & NA \\
\hline
\end{tabular}

PFS, progression-free survival; OS, overall survival; ORR, object response rate; AES, adverse events; Exp, experimental group; Con, control group; BEV, bevacizumab; CAR, carboplatin; IRI, iriontecan; TMZ, temozolomide; LOM, lomustin.; NA, not available.

chemotherapy was associated with a significantly better ORR (OR 1.85; 95\% CI 1.17-2.93; $p=0.009$ ). However, no heterogeneity was identified among the pooled studies $\left(\chi 2=0.60 ; p=0.74 ; \mathrm{I}^{2}=0 \%\right)$.

\section{AES}

Of the included studies, two reported the data of adverse events [20,23]. Adverse events of grade 3/4 listed in Table 1 were compared. As Figure 6 shows, the pooled estimates suggested that the combination therapy of bevacizumab and chemotherapy induced a significantly higher rate of high grade AES (OR 1.75; 95\% CI 1.09-2.83; $p=0.02$ ) compared with bevacizumab or chemotherapy alone. However, no heterogeneity was identified among the pooled studies $\left(\chi^{2}=1.27 ; p=0.26\right.$; $\left.\mathrm{I}^{2}=21 \%\right)$.

\section{DISCUSSION}

This study was a meta-analysis of RCTs and compares the combination of bevacizumab and chemotherapy to bevacizumab or chemotherapy alone in the treatment on GBMs. Our results show that, compared

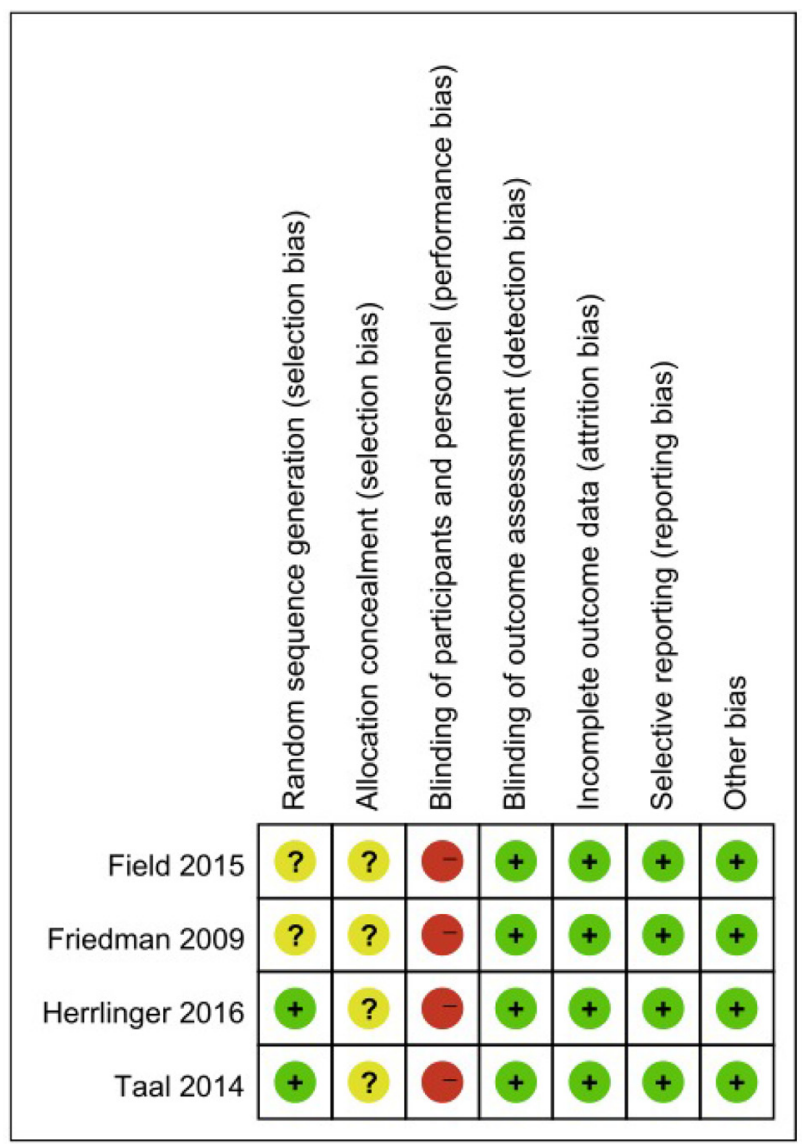

Figure 2: Risk of bias summary. Green circle, low risk of bias; Yellow circle, middle risk of bias; Red circle, high risk of bias. 
with a single-agent therapy, a combination treatment with bevacizumab and chemotherapy can yield improved PFS but not better OS in GBMs. A subgroup analysis in recurrent GBMs was also performed that resulted in the same conclusion. Additionally, compared with control group regimens, the combination regimen offers a greater ORR but more frequent grade 3/4 AES.

An article on meta-analysis of bevacizumab plus temozolomide- radiotherapy for newly diagnosed glioblastoma with different $\mathrm{O}^{6}$-methylguanine-DNA methyltransferase (MGMT) methylation status was published [24]. In that study, three clinical trials were included to assess the treatment efficacy. Their results presented that, compared with temozolomide and radiotherapy, bevacizumab combined with temozolomide and radiotherapy could improve PFS significantly in both MGMT methylated and unmethylated patients (pooled HRs, $0.77, p=0.032 ; 0.68, p=0.038$ ). However, the combination treatment could not prolong OS significantly (pooled HRs, 1.132, $p=0.345 ; 1.018, p=0.345$ ). Their conclusion was consistent with ours, in which PFS, but not OS, was improved compared with bevacizumab with chemotherapy to bevacizumab or chemotherapy alone. PENG FU reported a meta-analysis including the same three clinical trials with the study above and drew similar results of PFS (HR 0.71; 95\% CI 0.58-0.87; $p=0.001$ )

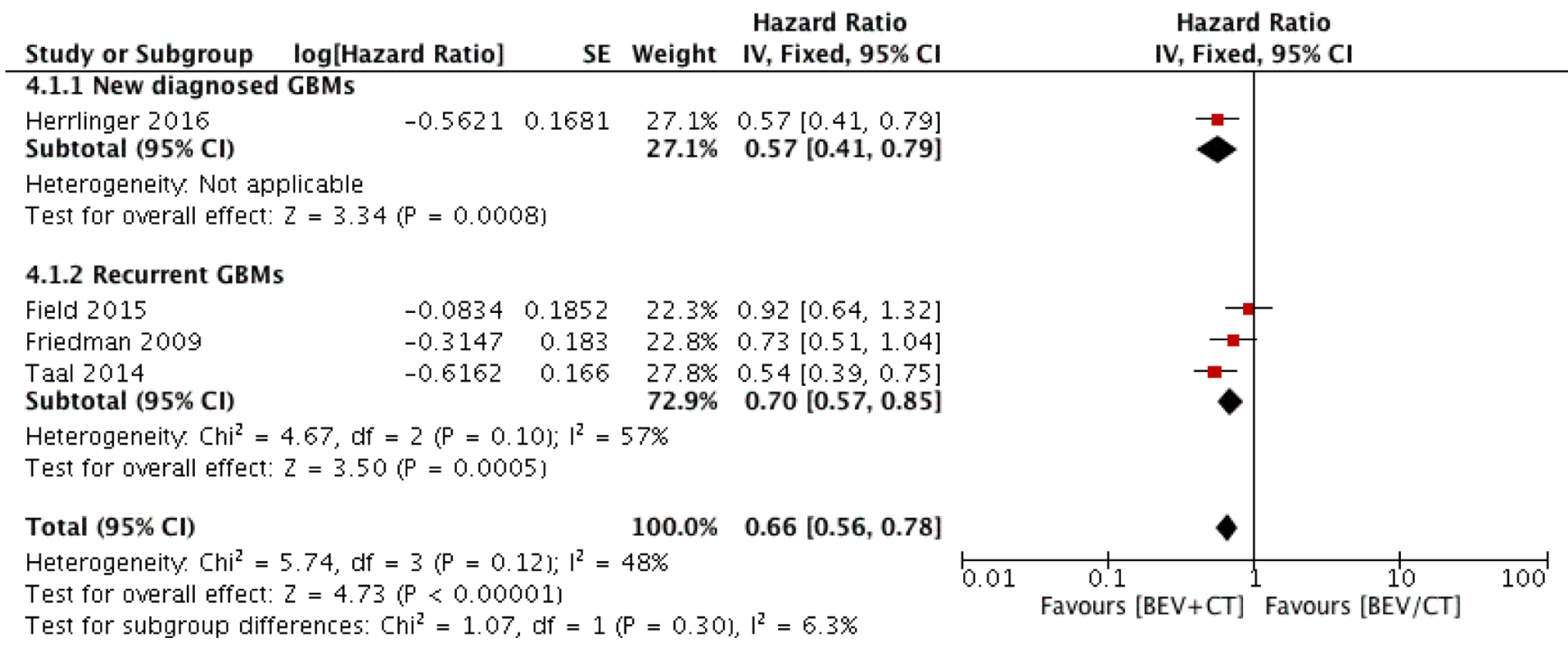

Figure 3: Progression-free survival for combination therapy of bevacizumab plus chemotherapy versus bevacizumab or chemotherapy alone.

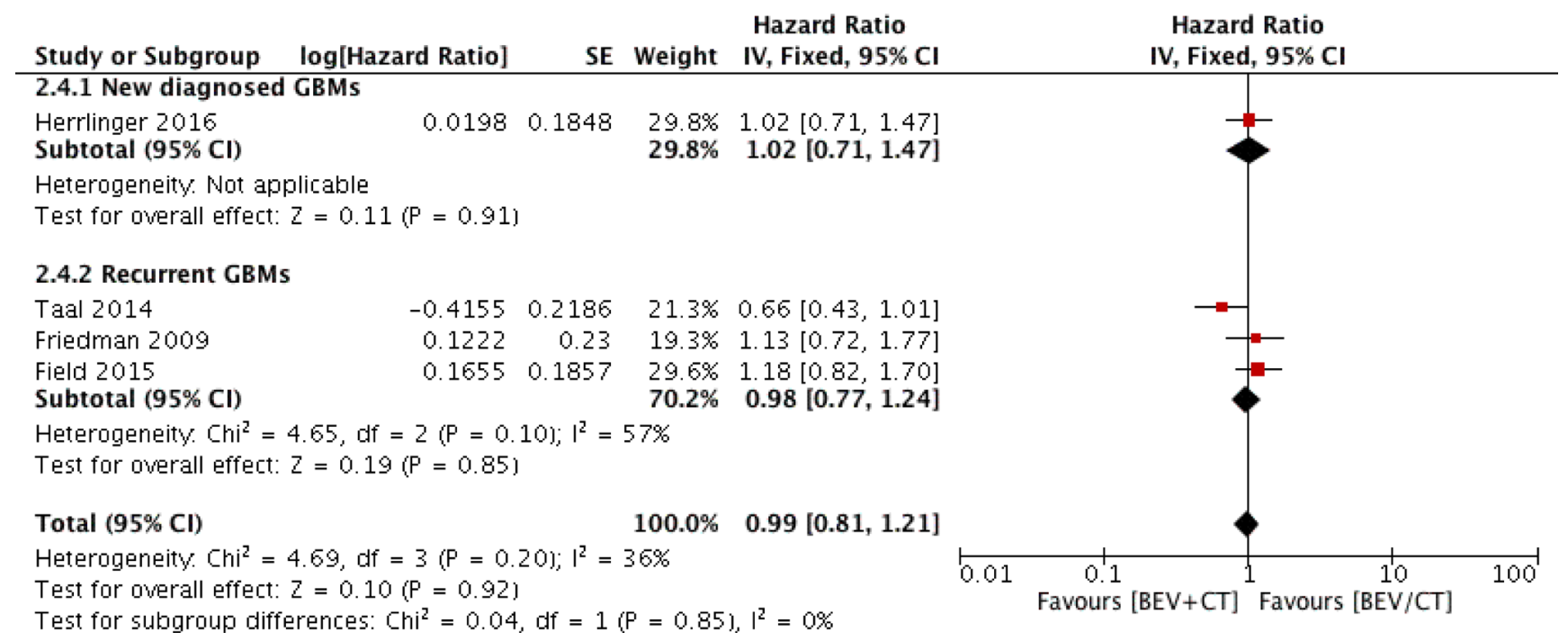

Figure 4: Overall survival for combination therapy of bevacizumab plus chemotherapy versus bevacizumab or chemotherapy alone. 
and OS (HR 0.99; 95\% CI 0.77-1.26; $p=0.04$ ) [25]. Furthermore, ORR and AES were analyzed by ORs to estimate the combination therapy of bevacizumab with chemotherapy.

Recurrent GBMs used irinotecan as a topoisomerase I inhibitor (PFS at 6 months 16\%) [26]. In a previous phase II trial of recurrent GBMs, bevacizumab in combination with irinotecan increased 6-month PFS to $46 \%$ [27]. In our pooled studies, Friedman reported a phase II, multicenter, open-label, non-comparative trial to estimate the efficacy of bevacizumab plus irinotecan for recurrent GBMs [20]. Compared with bevacizumab monotherapy, the combination treatment increased PFS-6 from $42.6 \%$ to $50.3 \%$ and ORR from $28.2 \%$ to $37.8 \%$. Median PFS was prolonged from 4.2 months to 5.6 months, but the PFS difference did not attain significance, calculated by the Kaplan-Meier curve (HR 0.73; 95\% CI 0.51-1.04; $p=0.085$ ). However, the OS benefit was not improved (median values from 9.2 months to 8.7 months) (HR $1.13 ; 95 \%$ CI $0.72-1.77 ; p=0.60$ ). Serious AES (grade 3/4) was experienced by $66 \%$ and $46 \%$ of patients in the combination and monotherapy group, respectively. Another phase II unblended trial assessed the efficacy of bevacizumab combined with irinotecan for newly diagnosed $\mathrm{O}^{6}$-methylguanine-DNA methyltransferase nonmethylated GBMs [21]. In this trial, control group regimen was temozolomide monotherapy. PFS-6 was increased from $42.6 \%$ with temozolomide to $79.3 \%$ with BEV+IRI $(p<0.001)$. The median PFS was prolonged from 5.99 months to 9.7 months (95\% CI, 8.7-10.8 months; $p<0.001)$. No statistical difference of OS was observed between the groups: the median OS was 17.5 months with temozolomide; and 16.6 months with bevacizumab plus irinotecan.

Carboplatin and lomustine were traditionally used cytotoxic drugs for GBMs, with typical response rates less than 20\%; PFS-6 has a response rate of around 15\%; OS is generally less than 6 months [28-30]. These two cytotoxic drugs have been involved with two trials in this meta-analysis. In a multicenter, randomized phase II trial, researchers explored the combination treatment of bevacizumab with carboplatin for recurrent GBMs [23]. That trial gained the same median PFS of 3.5 months for both groups (HR $0.92 ; p=0.66$ ). OS between the arms also showed insignificant difference (HR 1.18; $p=0.38$ ). AES in the trial was also recorded. The most frequent AES in the combination group were hematologic adverse events. Data for grade 3/4 AES with 64\% in combination group and $58 \%$ in control group $(p=0.52)$ were collected. BELOB trial studied the efficacy of bevacizumab plus lomustine in patients with recurrent GBMs [22]. The open-label, multicenter phase II study assigned eligible patients to three groups of bevacizumab or lomustine and bevacizumab and lomustine alone. The trial showed prolonged median PFSs with 1, 3, and 4 months in lomustine, bevacizumab, and bevacizumab or lomustine arm, respectively. Median OS was prolonged with 8, 8, and 12 months, respectively. However, difference of OS did not reach significance. As a method depicted above, the merged HR was calculated to represent outcomes with PFS $(\mathrm{HR} 0.54 ; p=0.0004)$ and OS (HR 0.66; $p=0.06)$ [17].

Bevacizumab was applied for recurrent GBMs due to a high ORR. ORR was thought to be correlated with prognosis of recurrent GBMs by several past studies [31, 32].

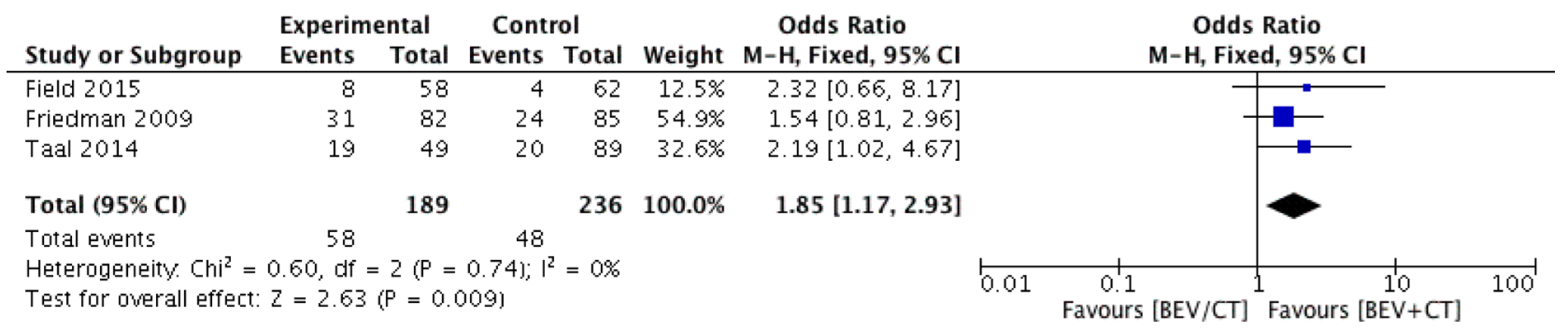

Figure 5: Object response rate for combination therapy of bevacizumab plus chemotherapy versus bevacizumab or chemotherapy alone.

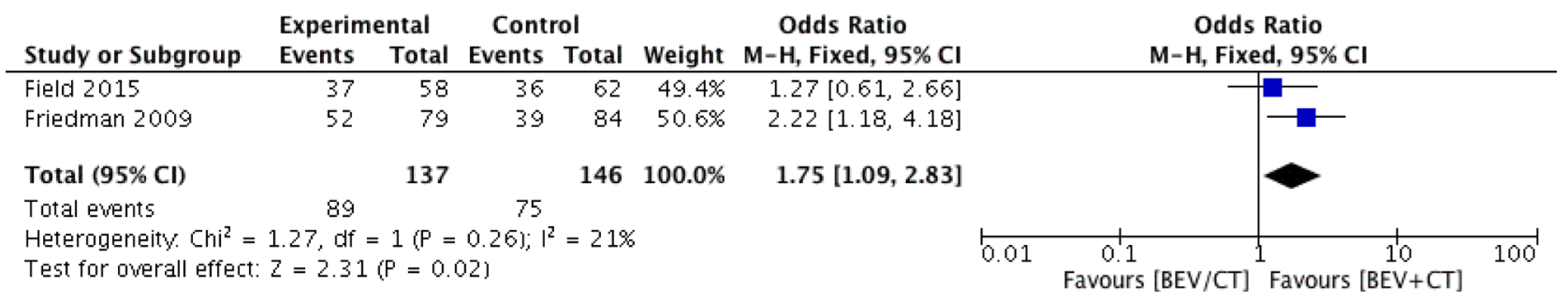

Figure 6: Adverse events for combination therapy of bevacizumab plus chemotherapy versus bevacizumab or chemotherapy alone. 
In BELOB trial, a trend was found and suggested that a higher ORR was associated with improved OS [22]. As Figure 5 presents, an analysis of ORR by data of three trials was performed to find that the bevacizumabcontaining group made better ORR than the monotherapy group [20, 22, 23]. However, prolonged OS was unproven. Different outcomes of PFS and OS are due to the fact that bevacizumab is a two-edged sword. After temporal antitumor effects with bevacizumab treatment, sequential hypoxia in GBM microenvironment may enhance invasion of GBM cells [33-36].

This study has some advantages. The four RCTs included were multicenter, large-scale, phase II trials that were well designed and well-performed [20-23]. The assessment of efficacy and safety with bevacizumab was assured to be of high reliability.

Consequently, this meta-analysis has several disadvantages worth noting. First, the number of pooled trials was relatively small; publication bias cannot be excluded. Second, patients in control groups received different treatment regimens: bevacizumab in two trials, temozolomide in one trial, and bevacizumab/lomustine in one trial [20-23]. These different treatment regimens may have an influence on estimated bevacizumab combination therapy. Third, an analysis was performed on overall grade 3/4 AES and subgroup analysis for recurrent GBMs because of insufficient data. Therefore, we look forward to more large-scale phase III trials to be conducted and enough information to perform a more powerful metaanalysis. However, these four eligible trials are still reliable, and our results will be helpful for physicians to make better decisions with bevacizumab treatment.

\section{MATERIALS AND METHODS}

\section{Search strategy}

This meta-analysis was registered at International Prospective Register of Systematic Reviews (number CRD42016047227) and was reported to adopt the Preferred Reporting Items for Systematic Reviews and MetaAnalyses (PRISMA) guidelines.

Relevant studies published in English, from January 1, 2009 to September 1, 2016, were selected by searching PubMed, Embase, and Cochrane. The following medical subject heading $(\mathrm{MeSH})$ terms were used for PubMed: ((Glioblastoma OR Glioma) OR (glioma* OR glioblastoma* OR glioblastoma multiforme) OR Astrocytoma*)) AND (Bevacizumab OR avastin) AND (randomized controlled trial OR controlled clinical trial OR randomized OR placebo OR clinical trials as topic OR randomly OR trial) NOT (animals NOT humans). The reference list of key articles was manually checked to prevent relevant articles from being excluded. Searching potential literature was done by two reviewers (Shou-Bo Yang and Kai-Di Gao), independently.

\section{Inclusion and exclusion criteria}

Studies were selected by the following criteria: (1) subjects were randomized control trials; (2) subjects are adults diagnosed with glioblastoma, irrespective whether primary or recurrent type; and (3) the two arms were treated with bevacizumab plus chemotherapy, bevacizumab, or chemotherapy alone. Furthermore, studies should not satisfy any exclusion criteria: (1) total subjects number was less than 30; and (2) the intervention of control arm was not chemotherapy or bevacizumab, but placebo.

\section{Data extraction and outcomes of interest}

The titles and abstract of all the studies identified in the literature search were screened by two reviewers (Shou-Bo Yang and Kai-Di Gao) to verify its compliance with the inclusion and exclusion criteria. The same reviewers independently extracted the data and assessed the quality of the publications. Disagreements between the two reviewers were resolved by consensus after a joint second review.

Information from included trials was extracted as follows: publication reference; recruitment period; patient characteristics; intervention regimens; number of events; and survival.

The PFS and OS rate were the primary outcome, whereas the object response rate (ORR) and treatmentrelated adverse events (AES) were the secondary outcome. ORR included complete responses (CRs) and partial responses (PRs). The authors were consulted for additional information for data excluded in the articles.

\section{Quality assessment}

The Cochrane Collaboration's tool was used to assess the risks of selection, performance, detection, attrition, and reporting biases in the RCTs selected for analysis. Trials with high-risk components of more than two were deemed to have a moderate risk of bias, whereas trials with high-risk components of more than four were deemed to have a high risk of bias.

\section{Data synthesis and analysis}

The time-to-event variables (OS and PFS) were assessed by hazard ratios (HRs) with $95 \%$ confidence intervals (CIs) for each study, and the dichotomous variables (ORR and AES) by ORs with 95\% CIs. In studies without direct HRs, Kaplan-Meier curves and follow-up period were used to calculate HRs [17]. One study assigned three groups and used the above-mentioned methods to calculate a merged HR with $95 \% \mathrm{CI}$ of the experimental group versus two control groups. A $p$ value less than 0.05 was considered statistically significant.

$\mathrm{I}^{2}$ testing was performed to assess the heterogeneity between studies, with values greater than $50 \%$ indicating 
significant heterogeneity. When significant heterogeneity was found, a random-effect model was used to analyze pooled studies; otherwise, a fixed-effects model was applied $[18,19]$. As the number of pooled studies was less than 10, publication bias was not assessed. Review Manager 5.3 (Cochrane Collaboration) was used for all statistical analyses.

\section{CONCLUSIONS}

Our meta-analysis suggested that the combination of bevacizumab and chemotherapy can improve PFS and ORR, significantly, but do not prolong OS. Moreover, combination treatment results in a more tolerable frequent grade 3/4 AES. Further studies focusing on the optimal regimen with bevacizumab are needed obtain best benefits to GBM patients.

\section{ACKNOWLEDGMENTS AND FUNDING}

The study was supported by intramural funds, with no commercial entity involved. We thank all of our colleagues who contributed to this meta-analysis.

\section{CONFLICTS OF INTEREST}

All the authors declare that there was no conflicts of interest.

\section{REFERENCES}

1. Ostrom QT, Gittleman H, Fulop J, Liu M, Blanda R, Kromer C, Wolinsky Y, Kruchko C, Barnholtz-Sloan JS. CBTRUS Statistical Report: Primary Brain and Central Nervous System Tumors Diagnosed in the United States in 2008-2012. Neuro Oncol. 2015; 17: iv1-iv62.

2. Stupp R, Mason WP, van den Bent MJ, Weller M, Fisher B, Taphoorn MJ, Belanger K, Brandes AA, Marosi C, Bogdahn U, Curschmann J, Janzer RC, Ludwin SK, et al. Radiotherapy plus concomitant and adjuvant temozolomide for glioblastoma. N Engl J Med. 2005; 352:987-996.

3. Das S, Marsden PA. Angiogenesis in glioblastoma. N Engl J Med. 2013; 369:1561-1563.

4. Plate KH, Scholz A, Dumont DJ. Tumor angiogenesis and anti-angiogenic therapy in malignant gliomas revisited. Acta Neuropathol. 2012; 124:763-775.

5. Gilbert MR, Dignam JJ, Armstrong TS, Wefel JS, Blumenthal DT, Vogelbaum MA, Colman H, Chakravarti A, Pugh S, Won M, Jeraj R, Brown PD, Jaeckle KA, et al. A randomized trial of bevacizumab for newly diagnosed glioblastoma. N Engl J Med. 2014; 370:699-708.

6. Plate $\mathrm{KH}$, Breier G, Weich HA, Risau W. Vascular endothelial growth factor is a potential tumour angiogenesis factor in human gliomas in vivo. Nature. 1992; 359:845-848.
7. Field KM, Jordan JT, Wen PY, Rosenthal MA, Reardon DA. Bevacizumab and glioblastoma: scientific review, newly reported updates, and ongoing controversies. Cancer. 2015; 121:997-1007.

8. Jain RK. Normalization of tumor vasculature: an emerging concept in antiangiogenic therapy. Science. 2005; 307:58-62.

9. Khasraw M, Lassman AB. Advances in the treatment of malignant gliomas. Curr Oncol Rep. 2010; 12:26-33.

10. Vredenburgh JJ, Desjardins A, Herndon JE 2nd, Dowell JM, Reardon DA, Quinn JA, Rich JN, Sathornsumetee S, Gururangan S, Wagner M, Bigner DD, Friedman AH, Friedman HS. Phase II trial of bevacizumab and irinotecan in recurrent malignant glioma. Clin Cancer Res. 2007; 13:1253-1259.

11. Kreisl TN, Kim L, Moore K, Duic P, Royce C, Stroud I, Garren N, Mackey M, Butman JA, Camphausen K, Park J, Albert PS, Fine HA. Phase II trial of single-agent bevacizumab followed by bevacizumab plus irinotecan at tumor progression in recurrent glioblastoma. J Clin Oncol. 2009; 27:740-745.

12. Narayana A, Kelly P, Golfinos J, Parker E, Johnson G, Knopp E, Zagzag D, Fischer I, Raza S, Medabalmi P, Eagan P, Gruber ML. Antiangiogenic therapy using bevacizumab in recurrent high-grade glioma: impact on local control and patient survival. J Neurosurg. 2009; 110:173-180.

13. Ahluwalia MS, Gladson CL. Progress on antiangiogenic therapy for patients with malignant glioma. J Oncol. 2010; 2010:689018.

14. Lamszus K, Kunkel P, Westphal M. Invasion as limitation to anti-angiogenic glioma therapy. Acta Neurochir Suppl. 2003; 88:169-177.

15. Pope WB, Lai A, Mehta R, Kim HJ, Qiao J, Young JR, Xue X, Goldin J, Brown MS, Nghiemphu PL, Tran A, Cloughesy TF. Apparent diffusion coefficient histogram analysis stratifies progression-free survival in newly diagnosed bevacizumab-treated glioblastoma. AJNR Am J Neuroradiol. 2011; 32:882-889.

16. Norden AD, Young GS, Setayesh K, Muzikansky A, Klufas R, Ross GL, Ciampa AS, Ebbeling LG, Levy B, Drappatz J, Kesari S, Wen PY. Bevacizumab for recurrent malignant gliomas: efficacy, toxicity, and patterns of recurrence. Neurology. 2008; 70:779-787.

17. Tierney JF, Stewart LA, Ghersi D, Burdett S, Sydes MR. Practical methods for incorporating summary time-to-event data into meta-analysis. Trials. 2007; 8:16.

18. Mantel N, Haenszel W. Statistical aspects of the analysis of data from retrospective studies of disease. J Natl Cancer Inst. 1959; 22:719-748.

19. DerSimonian R, Kacker R. Random-effects model for metaanalysis of clinical trials: an update. Contemp Clin Trials. 2007; 28:105-114.

20. Friedman HS, Prados MD, Wen PY, Mikkelsen T, Schiff D, Abrey LE, Yung WK, Paleologos N, Nicholas MK, Jensen R, Vredenburgh J, Huang J, Zheng M, Cloughesy T. 
Bevacizumab alone and in combination with irinotecan in recurrent glioblastoma. Journal of Clinical Oncology. 2009; 27:4733-4740.

21. Herrlinger U, Schafer N, Steinbach JP, Weyerbrock A, Hau P, Goldbrunner R, Friedrich F, Rohde V, Ringel F, Schlegel U, Sabel M, Ronellenfitsch MW, Uhl M, et al. Bevacizumab Plus irinotecan versus temozolomide in newly diagnosed $\mathrm{O}^{6}$-methylguanine-DNA methyltransferase nonmethylated glioblastoma: The randomized GLARIUS trial. Journal of Clinical Oncology. 2016; 34:1611-1619.

22. Taal W, Oosterkamp HM, Walenkamp AM, Dubbink HJ, Beerepoot LV, Hanse MC, Buter J, Honkoop AH, Boerman D, de Vos FY, Dinjens WN, Enting RH, Taphoorn MJ, et al. Single-agent bevacizumab or lomustine versus a combination of bevacizumab plus lomustine in patients with recurrent glioblastoma (BELOB trial): a randomised controlled phase 2 trial. Lancet Oncol. 2014; 15:943-953.

23. Field KM, Simes J, Nowak AK, Cher L, Wheeler H, Hovey EJ, Brown CS, Barnes EH, Sawkins K, Livingstone A, Freilich R, Phal PM, Fitt G, et al. Randomized phase 2 study of carboplatin and bevacizumab in recurrent glioblastoma. Neuro Oncol. 2015; 17:1504-1513.

24. Du C, Ren J, Zhang R, Xin T, Li Z, Zhang Z, Xu X, Pang Q. Effect of Bevacizumab Plus Temozolomide-Radiotherapy for Newly Diagnosed Glioblastoma with Different MGMT Methylation Status: A Meta-Analysis of Clinical Trials. Medical Science Monitor. 2016; 22:3486-3492.

25. Fu P, He YS, Huang Q, Ding T, Cen YC, Zhao HY, Wei X. Bevacizumab treatment for newly diagnosed glioblastoma: Systematic review and meta-analysis of clinical trials. Mol Clin Oncol. 2016; 4:833-838.

26. Prados MD, Lamborn K, Yung WK, Jaeckle K, Robins HI, Mehta M, Fine HA, Wen PY, Cloughesy T, Chang S, Nicholas MK, Schiff D, Greenberg H, et al. A phase 2 trial of irinotecan (CPT-11) in patients with recurrent malignant glioma: a North American Brain Tumor Consortium study. Neuro Oncol. 2006; 8:189-193.

27. Vredenburgh JJ, Desjardins A, Herndon JE 2nd, Marcello J, Reardon DA, Quinn JA, Rich JN, Sathornsumetee S, Gururangan S, Sampson J, Wagner M, Bailey L, Bigner DD, et al. Bevacizumab plus irinotecan in recurrent glioblastoma multiforme. J Clin Oncol. 2007; 25:4722-4729.
28. Batchelor TT, Mulholland P, Neyns B, Nabors LB, Campone M, Wick A, Mason W, Mikkelsen T, Phuphanich S, Ashby LS, Degroot J, Gattamaneni R, Cher L, et al. Phase III randomized trial comparing the efficacy of cediranib as monotherapy, and in combination with lomustine, versus lomustine alone in patients with recurrent glioblastoma. J Clin Oncol. 2013; 31:3212-3218.

29. Nieder C, Grosu AL, Molls M. A comparison of treatment results for recurrent malignant gliomas. Cancer Treat Rev. 2000; 26:397-409.

30. Wong ET, Hess KR, Gleason MJ, Jaeckle KA, Kyritsis AP, Prados MD, Levin VA, Yung WK. Outcomes and prognostic factors in recurrent glioma patients enrolled onto phase II clinical trials. J Clin Oncol. 1999; 17:2572-2578.

31. Prados M, Cloughesy T, Samant M, Fang L, Wen PY, Mikkelsen T, Schiff D, Abrey LE, Yung WK, Paleologos N, Nicholas MK, Jensen R, Vredenburgh J, et al. Response as a predictor of survival in patients with recurrent glioblastoma treated with bevacizumab. Neuro Oncol. 2011; 13:143-151.

32. Boxerman JL, Zhang Z, Safriel Y, Larvie M, Snyder BS, Jain R, Chi TL, Sorensen AG, Gilbert MR, Barboriak DP. Early post-bevacizumab progression on contrast-enhanced MRI as a prognostic marker for overall survival in recurrent glioblastoma: results from the ACRIN 6677/RTOG 0625 Central Reader Study. Neuro Oncol. 2013; 15:945-954.

33. Paez-Ribes M, Allen E, Hudock J, Takeda T, Okuyama H, Vinals F, Inoue M, Bergers G, Hanahan D, Casanovas O. Antiangiogenic therapy elicits malignant progression of tumors to increased local invasion and distant metastasis. Cancer Cell. 2009; 15:220-231.

34. Keunen O, Johansson M, Oudin A, Sanzey M, Rahim SA, Fack F, Thorsen F, Taxt T, Bartos M, Jirik R, Miletic H, Wang J, Stieber D, et al. Anti-VEGF treatment reduces blood supply and increases tumor cell invasion in glioblastoma. Proc Natl Acad Sci USA. 2011; 108:3749-3754.

35. Furuta T, Nakada M, Misaki K, Sato Y, Hayashi Y, Nakanuma Y, Hamada J. Molecular analysis of a recurrent glioblastoma treated with bevacizumab. Brain Tumor Pathol. 2014; 31:32-39.

36. Ebos JM, Lee CR, Kerbel RS. Tumor and host-mediated pathways of resistance and disease progression in response to antiangiogenic therapy. Clin Cancer Res. 2009; 15:5020-5025. 